\title{
Evaluation of the belt punching process efficiency based on the resistance force of the compressed material
}

\author{
Dominik Wojtkowiak $^{1} \cdot$ Krzysztof Talaśka $^{1} \cdot$ Dominik Wilczyński $^{1}$
}

Received: 7 June 2020 / Accepted: 21 July 2020 / Published online: 15 August 2020

(C) The Author(s) 2020

\begin{abstract}
Vacuum conveyor belt punching process by using the piercing punch which cooperates with the die has potential to be modified in aspects of lowering the perforation force, extending the tool life, and improving the hole quality in the perforated belts. All these parameters have an influence on the efficiency of the process and strictly depends on the punch geometry. This indicates that based on these criteria the optimization of the tool constructional features may be performed. In the presented research, authors have shown the linear correlation between the resistance force of the compressed material of the multilayer polymer composite belt in punching and the efficiency of the process. It was also proved that using the effective geometry of the piercing punch with spherical bowl can reduce the perforation force by $69 \%$. Based on the obtained model, the simplified optimization as well as the evaluation of the punches with defined geometry can be performed, since all characteristics of the material compressive force obtained for the effective punches were almost consistent. For proper analysis, it is necessary to use the combination of the analytical and numerical modelling, computer simulations with using the finite element method (FEM) and the experimental tests. However, by performing simple compression tests for various tool geometry on the strength testing machine, it is possible to perform the comparison analysis of different piercing punches based on the derived models. This approach can be used to evaluate the properties of selected tools for the groups of materials with wide divergence of the mechanical properties without performing the complex research.
\end{abstract}

Keywords Belt perforation · Piercing punch · Tool sharpness - FEM optimization · Manufacturing quality control · Spherical bowl punch

\section{Introduction}

Sheet metal punching is widely discussed in the scientific literature and seems to be a rather simple manufacturing process compared with different mechanical working operations or the machining operations. For example, Soares et al. [1] studied the influence of the punch-die clearance on the sheared edge quality and force necessary to pierce the metal sheet and stated that the clearance between 2 and 5\% causes smaller peak of maximum punch force and lower fracture angle. Mucha and Tutak [2] analyzed the correlation between the clearance and tool wear and proved

Dominik Wojtkowiak

dominik.wojtkowiak@put.poznan.pl

1 Faculty of Mechanical Engineering, Institute of Machine Design, Poznan University of Technology, Piotrowo 3 street, 61-138, Poznań, Poland that decreasing clearance (up to 5\%) results in lower initial burr values. Vinod and Shivashankar [3] have presented the recent technological advances in sheet metal forming processes. Based on their analysis, the significant role of the finite element method (FEM)-based simulation in the blanking optimization was highlighted. Such parameters as punch-die clearance, sheet thickness, friction and punch radius, etc. were defined as the ones with influence on the technological process efficiency. Similar conclusions were also presented for the deep drawing process by Djavanroodi et al. [4]. They proved that decreasing the punch radius leads to lowering the initial pressure and that smaller friction causes increase of the safe zone.

Although by using FEM analysis, we can improve the technical aspects of the sheet metal punching process by modifying the constructional features of the punching dies, multiple handbooks like [5], which contain design briefs and useful correlations between the geometrical or material parameters and technical aspects of the final device can be found. However, this data is not always valid for softer and 
more elastic materials like multilayer polymer composite belts, as was proved by Wojtkowiak and Talaśka [6].

The belt punching seems to be a much easier technological operation to perform, but due to the variety of the mechanical properties of the multilayer polymer composite belts it causes a lot of technical problems for perforated belts manufacturers worldwide [7]. Spagnoli et al. [8] experimented on cutting both hard and soft polymeric materials and described the mechanics of fracture which occurs in these materials. They also stated that the blade sharpness depends on the blade profile as well as material toughness and deformability. Since multilayer polymer composite belts are often the combination of both types of the abovementioned materials, it proves that punching them is complex process and may be difficult for certain combination of properties. Durante et al. [9] noticed that carbon fiber reinforced plastics are prone to delaminate during drilling and because of the presence of this defect the products can be rejected. They have also presented their influence on the cutting force and delamination factor. Anand and Patra [10] discussed the difficulties of CFRP micro-drilling due to anisotropic, abrasive, and non-homogenous properties and how they have an effect on the hole quality and cutting forces. The analysis of using different mechanical and nonmechanical methods was presented by Wojtkowiak et al. [7] and perforation by punching was chosen as the most suitable method. A series of experimental tests were performed and proved the influence of the geometrical and process parameters on the three main technical aspects: quality of the perforated belt, force necessary to punch the hole in the belt, and tool life or cutting edge wear. Chan et al. [11] studied the effect of die clearance on the punched holes quality of composite panels and established it should have been minimized. Zain et al. [12] verified the effect of the puncher profile on the precision of punched holes on composite panels and have selected the conical shape puncher as effective one. Wojtkowiak et al. [13] have analyzed various modified shapes of the piercing punch for the multilayer polymer composite belts and proved that concave punches provide the best results. Wojtkowiak and Talaśka [14] compared spherical and conical bowl punches and proposed a spherical bowl punch as an effective one for polymer composite belts.

Wojtkowiak et al. [13] also proposed the model for estimation of the perforation force for belts with polyamide core and its application in the FEM modelling of the belt punching process. Based on these data, Wojtkowiak and Talaśka [6] performed optimization of the spherical bowl geometry, with the use of FEM analysis, experimental results, and numerical calculations supported by an analytical model. Multiple correlations which are valid for the belt perforation process, where the punch velocity and temperature are the variables, were also showed by Wojtkowiak et al. [15, 16]. The methodology of modelling such a process and using these data in the punching die design process was presented by Wojtkowiak and Talaśka [16].

Although the available scientific studies allow to improve the belt punching process in a satisfactory way, it still requires rather complex analysis and does not take into consideration the manufacturing quality of the piercing punch. As was proved by Wojtkowiak and Talaśka [6], there is a wide spread of the perforation force measurement for tools with the same geometry but various tool conditions. Due to the complex machining of the spherical bowl punches, multiple sources of the errors can be detected, like geometric and kinematic errors of the machine, thermal errors, or deflection of the cutting tool errors [17]. This is why it is important to be able to evaluate the sharpness of the spherical bowl punch in order to predict the tool performance and facilitate the product quality control in the tool manufacturing process.

If we analyze the available methods of testing the sharpness of the cutting edge, none of them is suitable enough to achieve satisfactory and explicit results. Generally, we can distinguish contact and non-contact methods of testing the sharpness of the tool cutting edge as was presented in the review of the evaluation methods and models of cutting sharpness made by Reilly et al. [18]. Contact methods are mostly based on the measurement of the force which needs to be generated by the drive system in order to perform the technological process. The correlation between the sharpness and the cutting force was proved in multiple pieces of research. The significant impact was made by McCarthy $[19,20]$, who introduced the sharpness indicator BSI (Blade Sharpness Index) based on the energy criteria, which should not be material relevant, but takes into consideration the blade angle, edge straightness, and blade radius. Schuldt et al. [21] presented the methodology of the sharpness evaluation based on the cutting force for an elastomer. It is very useful in the tool condition monitoring systems, which measure the force value in real time and provide information when the loss of the process efficiency exceeds the limit value. However, this approach is not advantageous for the tool manufacturers in the quality control process since it requires to have the machinery for which the tools are made.

Much more appropriate for this application are the noncontact methods, which are mostly based on the correlation between the cutting edge defects or wear and the sharpness of the tool. Lau et al. [22] have used in their research scanning electron microscope on the surface of the cutting blade in order to check the wear level and in effect evaluate the sharpness. Van Woerden [23] used the diffraction of the laser light which was pointed at the knife tip and vision detection of the light intensity levels measured at various angles to determine the sharpness of the knife. Lu et al. 
[24] proposed the hybrid type instrument which is capable of both contact and non-contact measurement by using optical displacement sensor. In this paper, it was proved that the resolution of non-contact method was two times better than the contact one. Sandak et al. [25] have compared various optical methods of measuring the geometry of the cutting tool and stated that shadow triangulation is the most reliable method, while using laser micrometer is the most suitable for in-line application. Patel et al. [26] used the vision systems in which the sharpness is defined based on the image evaluation. However, these systems are very expensive and require the knowledge to define the effect of the observed defects on the sharpness, which is not possible without experimental research. Of course, a few industrial and patented systems for sharpness measurement can be found, which use both contact and non-contact methods, but their application is restricted to specific cutting tools like straight edge knives or disk blades. Flisram et al. [27] proposed the apparatus which makes a test cut in the standard specimen and the peak cutting force is measured. Lebouitz and Migliuolo [28] stated that mounting the semiconductor sensor in the cutting device may be useful to evaluate its sharpness. Lebeau [29] presented a method of an optical sharpness meter for measuring and quantifying the degree of sharpness. Also one industrial cutting test machine for knifes and blades can be found [30].

None of these methods meets the requirement to evaluate the efficiency of the belt perforation process in the explicit way without taking time-consuming and expensive actions. The most adequate method to evaluate the quality of the punch after machining is precise measurement of the punch geometry with using either a non-contact or contact gauge head since the correlation between the punch geometry and its performance has been already proved in [6]. But for the spherical bowl punches, it could be difficult due to a closed contour of the cutting edge and rather small diameters. This is why it is desired to develop a simple method to evaluate the ability of the tool to reach a certain efficiency of the belt perforation process, what is the goal of the paper.

In this paper, the authors presented the correlation between the compressive force of the material and the efficiency of the belt perforation process, which can be evaluated by the peak perforation force value. This correlation was used to develop a novel methodology of evaluation of the cutting edge condition and as a result the efficiency of the belt perforation process for the punches with spherical bowl. The research is focused on vacuum belt perforation, which is still an unknown issue, but the presented data helped to better understand its nature. It was also proved that the correlation between the compressive force of the material and the effective geometry of the piercing punch exists. It may result in greatly improving the tool optimization process. Although the object of research is the polymer composite belt, the obtained results and characteristics may be useful for different materials as well. The research was conducted based on the combination of the FEM analysis and experimental tests whose methodology is described in Section 2. The results and discussion presented in Section 3 lead to the proposal of the application of the derived correlations in the tools cutting edge quality control for punches used for belt perforation, which is clearly stated in the conclusions (Section 4).

\section{Materials and methods}

Polymer multilayer composite belts can be divided into three groups [7]: light elastic belts, high strength rigid belts, and elastic belts with increased strength. In this research, the representatives of the first two groups were used, since they are characterized with extremely different mechanical properties. The structure of these belts is presented in Fig. 1. Light elastic belt LAB12E is made of the polyurethane TPE, which is reinforced with polyester (PES) fabric. To increase

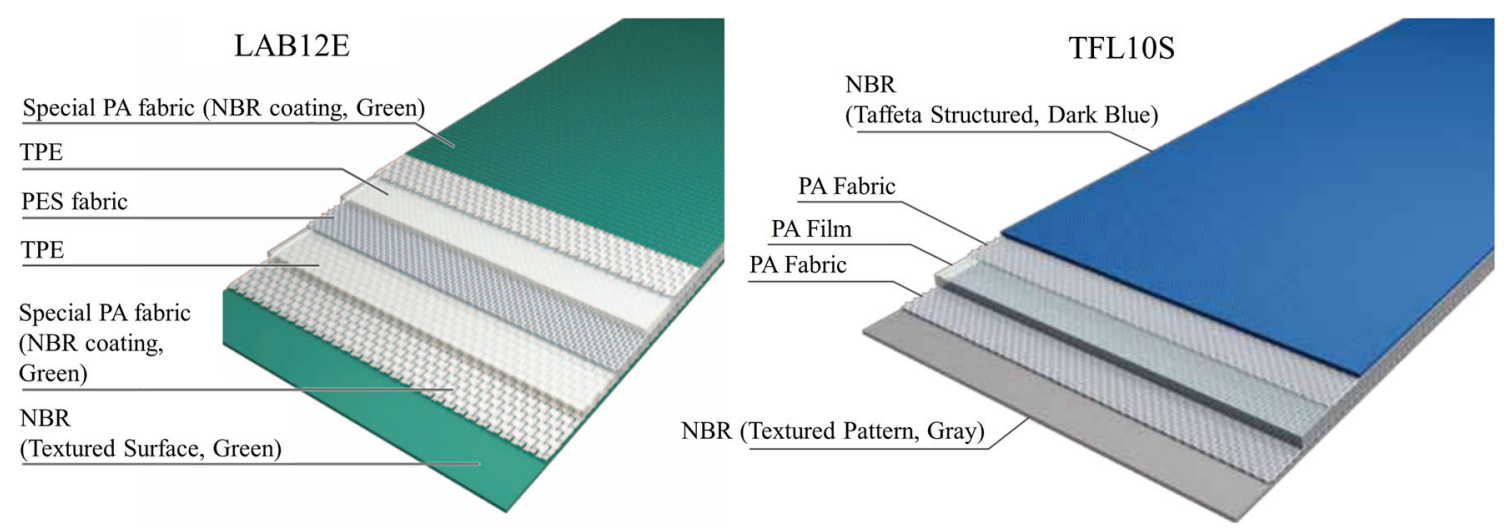

Fig. 1 Example of the structure of the multilayer polymer composite belts on the basis of FZ-5E12 (a) and TFL10S (b) belts (PolySprint $囚$ [39]) 
its grip, it was coated with the special polyamide fabric on the treading side and with the NBR rubber on the loading side. The rigid belt TFL10S, with very high strength, has a core made of a 1-mm-thick polyamide film which is protected with two protective gaskets made of polyamide fabric. Both sides of the belt are coated with NBR rubber. The main research was conducted for the TFL10S belt, while the LAB12E belt was used to verify the correctness of the presented correlations.

The conducted research was divided into two stages. In the first one, the resistance force of the material $F_{M}$ was derived based on the FEM analysis results and the analytical model of the load distribution for the spherical bowl punch during perforation [6]. Based on this model, the value of material resistance is not constant, due to the non-linear pressure area change (distance $x(h)$-Eq. 1) as the punch penetrates the belt. It can be determined as presented in Fig. 2 and Eqs. 2-4:

$x(h)=\frac{1}{2} D-\sqrt{\frac{1}{4} D^{2}-2 h \sqrt{R^{2}-\frac{1}{4} D^{2}-h^{2}}}$

$F_{M}=\frac{\sum_{i=1}^{n} F_{M i}}{n}$,

$F_{M i}=k_{x i} \cdot h_{i}$

$k_{x i}=\frac{E \cdot \pi D \cdot x}{t}$

where $D$ is the punch diameter, $R$ is the punch bowl radius, $h$ is the depth of the penetration, $x$ is distance of the pressure area between the punch and belt, $t$ is the thickness of the belt, and $E$ is Young's modulus of the belt.

However, if we analyze the load distribution, we can derive the resistance of the material knowing the perforation force $F_{P}$ and the friction force $F_{F}$ (Eq. 5). Both of these values can be obtained from the FEM analysis results and a set of numerical calculations performed on the basis of the analytical model [6]. This approach was used in the presented research.

$F_{M}=\frac{1}{2} F_{P}-F_{F} \sin \alpha$

The FEM model used in the research to analyze various geometries of the punches was constructed in ABAQUS Explicit as presented in Fig. 3. The model consists of four instances, but only the belt is modelled as a deformable part, while others are treated as rigid bodies. The piercing punch was meshed with tetrahedral C3D10M elements due to the complex geometry, while the rest of the parts were meshed with hexahedral, 3D stress, linear C3D8R explicit elements. The size of the finite elements was adjusted in such a way that 10 elements were distributed on the thickness of the belt while the circumference of the punched hole was divided into 100 elements. The material of the belt was modelled using isotropic properties with equivalent parameters and for the damage modelling the Johnson-Cook model was used. Simplifying anisotropic materials like natural composites (wood, bamboo) or engineering composites (fiber reinforced polymer composites or metal composites) using either orthotropic or transversely isotropic model is commonly used [31, 32], especially in machining simulations for composites. Examples of successfully using JohnsonCook plasticity model for composite materials can be found in the literature as well [33, 34], while this model is applicable for isotropic material only. More detailed justification of using such simplification of the orthotropic structure of the belt is presented in [13] and [35].
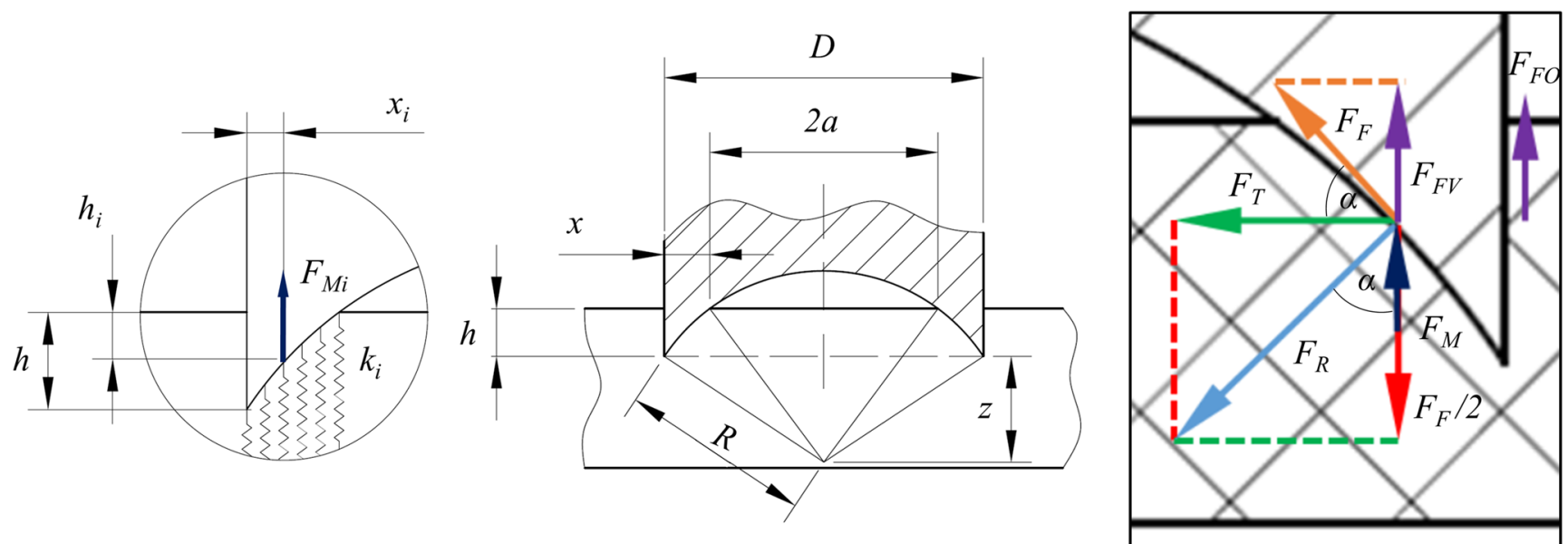

Fig. 2 Methodology of modelling the resistance force of the material during belt perforation with spherical bowl punch [6]: $F_{P}$, perforation force; $F_{T}$, transverse force; $F_{R}$, radial force; $F_{F}$, friction on the inside surface of the bowl; $F_{F O}$, friction on the side surface of the punch; $F_{M}$, material resistance force 


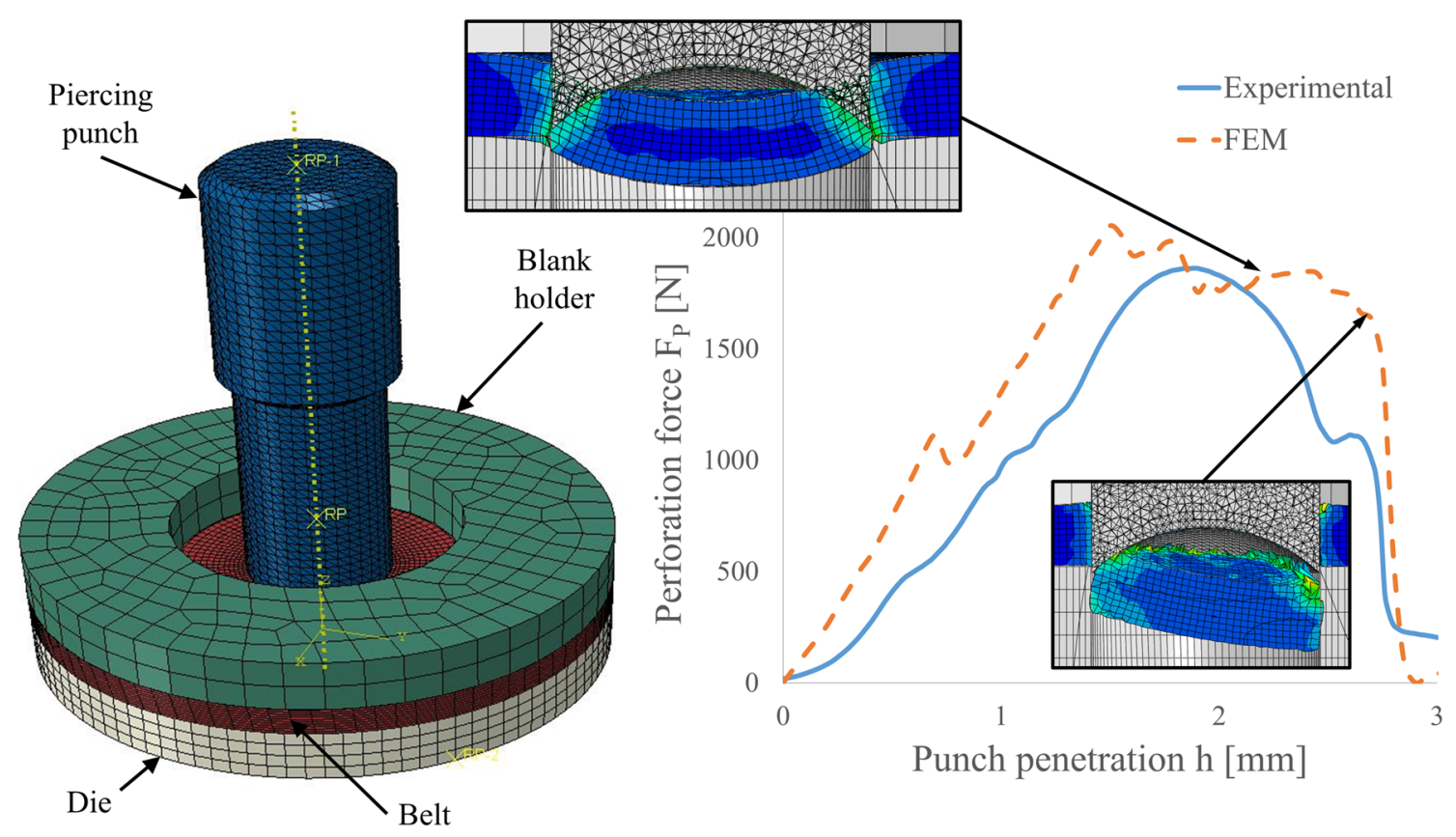

Fig. 3 Construction of the FEM model in ABAQUS and sample results of the analysis [6]

The contact between the belts and the tools was set as tangential behavior friction with the coefficient of 0.6 and hard contact in the normal directions. The frictional behavior in the real conditions is much more complex due to the layer structure of the belt. However, since the homogenization of the material was performed using average mechanical properties, the friction coefficient is also treated as constant value. The kinematic extortion of the piercing punch with velocity $0.5 \mathrm{~mm} / \mathrm{s}$ was set as a boundary condition in order to maintain the quasi-static nature of the process and neglect the influence of punch velocity. The analysis lasts $10 \mathrm{~s}$ and the mass scaling with target time increment was set as 0.001 to reduce the computational time without affecting the results. The main parameters used in the analysis are presented in Table 1. A more detailed description of the model along with its validation can be found in [6].

The second stage of the research was concerned with the experimental tests of both perforation force and resistance force of the compressed belt values for various geometry of the piercing punches with a spherical bowl punch. Both these tests were made for five different punches with diameter $D=10 \mathrm{~mm}$ and various punch radius $R=5.5$, $6.5,7.25,8.5$, and $10 \mathrm{~mm}$. Each test was repeated 5 times to obtain reliable data. The results of the measurement of the perforation force along with the construction of the punching die used for it were already presented [6] or [13] and they were used to determine the effective geometry of the spherical bowl punch. In order to expand the research, extra four punches which were defined as effective ones based on research [6] for diameters $D=5,6,8$, and $10 \mathrm{~mm}$ (with radiuses $R=2.9,3.5,4.8$, and $6 \mathrm{~mm}$ respectively) were also tested. The set of tools used in the research is presented in Fig. 4.

Based on the observations during previous research, it was assumed that there has to be a correlation between the resistance force of the compressed material of the multilayer polymer composite belt during punching and the efficiency of the process, which can be evaluated based on the perforation force value. Because of this, it is possible to develop a simple testing methodology of the compressive resistance force, which will enable evaluating the tool condition in the quality control process. The construction of the applied test stand is presented in Fig. 4. It consists of the strength testing machine MTS Insight $50 \mathrm{kN}$ along with its gripper in which the punch chuck is mounted. The tested tool is embedded inside the punch socket in the chuck and blocked with a forelock. The belt lies on

Table 1 Parameters used in the FEM analysis [6]

\begin{tabular}{lllllll}
\hline Density & Young's modulus & Poisson ratio & \multicolumn{2}{l}{ Johnson-Cook model parameters } \\
\hline$\rho\left[\mathrm{kg} / \mathrm{m}^{3}\right]$ & $E[\mathrm{MPa}]$ & $v[-]$ & $d_{1}[-]$ & $d_{2}[-]$ & $d_{3}[-]$ & $d_{4}[-]$ \\
1140 & 235 & 0.2 & -0.24 & 0.32 & 2.6 & 0 \\
\hline
\end{tabular}




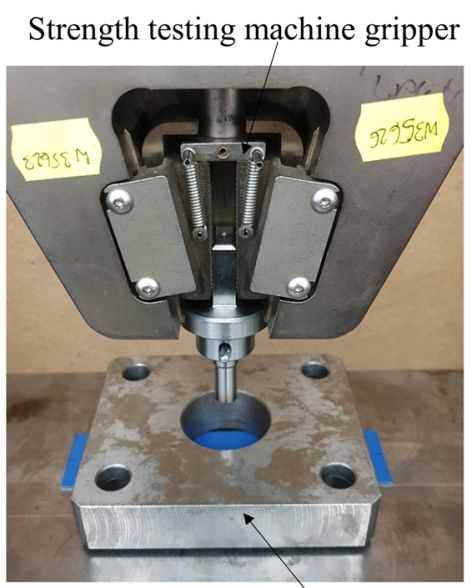

Blank holder

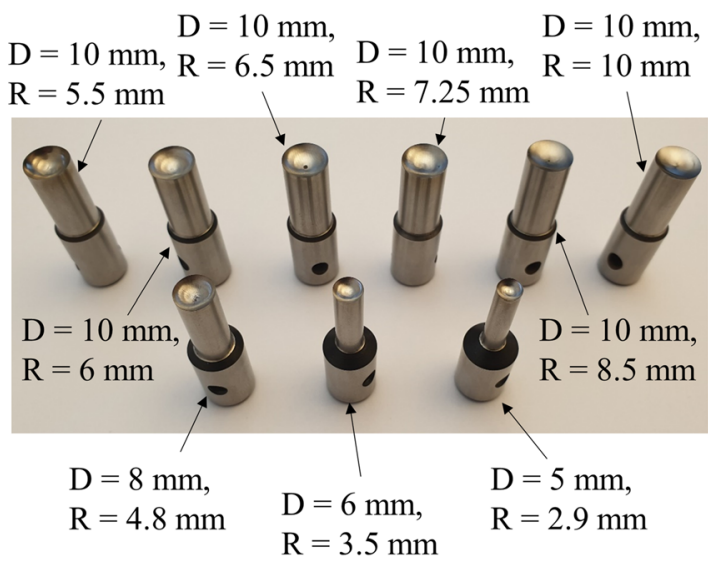

TFL10S belt

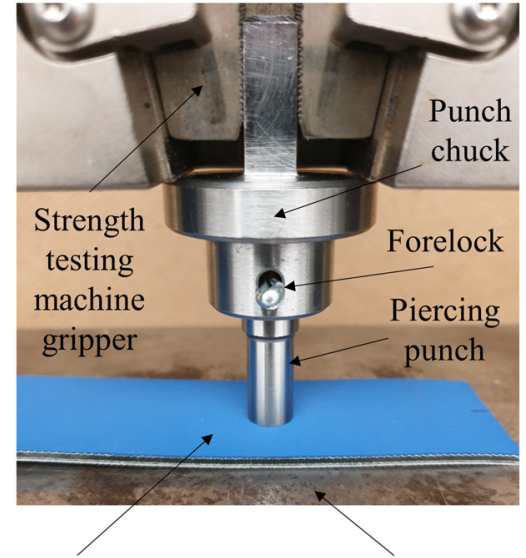

Support plate

Fig. 4 Test stand used to measure the compressive force and set of tested punches

the flat support plate at the bottom of the strength testing machine and is held by the blank holder to maintain belt flatness. During the test, the compressive force in function of the punch displacement is measured. The test ends at a specific penetration depth inside the belt, which is specified based on the polymer multilayer composite belt structure and its thickness. The main advantage of the presented methodology is that there is no requirement for specific machinery in the manufacturing facility and the results are easy to analyze. Similar examples can be found in literature. For example, Bassoli et al. [36] used this approach in testing the restraining force in deep drawing where the common tensile test was used. Zhou and McMurray [37] applied similar methodology for testing chirurgical cutting tools where they are using the compressive force to predict the required cutting force. Also McGorry et al. [38] proposed simple sharpness tester on similar basis of using a motion that is representative for meat cutting to test kitchen knives.

\section{Results and discussion}

Based on the presented methodology, the material resistance force characteristics in function of the punch displacement for all the analyzed punches and the belt TFL10S were derived. Sample results for the spherical bowl punch with diameter $D=10 \mathrm{~mm}$ and radius $R=6 \mathrm{~mm}$ are presented in Fig. 5. As can be observed, the material resistance increases until the punch penetrates approximately half of the belt thickness $(t=2.65 \mathrm{~mm})$ and after that the force value starts to decrease. It is caused by the fracture of the core of the belt, since it was reached by the cutting edge of the piercing
Fig. 5 Material resistance force characteristic in function of punch displacement for the TFL10S belt and a spherical bowl punch with a diameter $D=$ $10 \mathrm{~mm}$ and radius $R=6 \mathrm{~mm}$

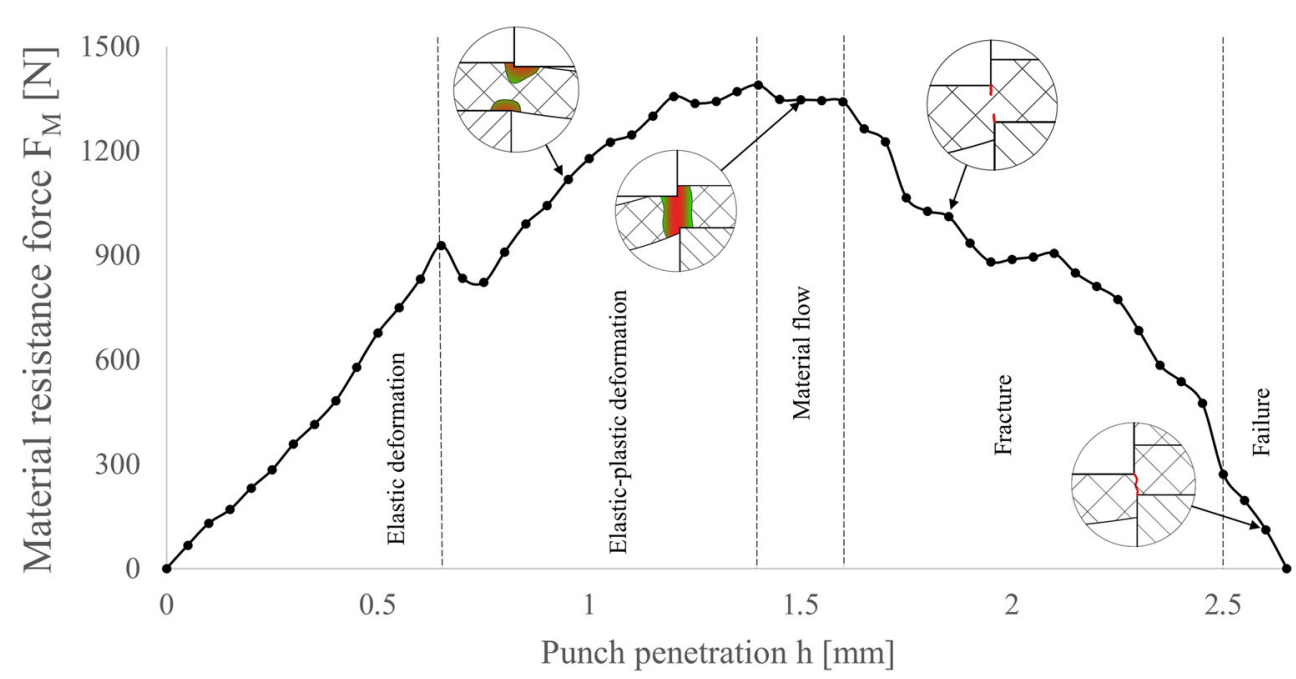


punch and the limit strain was exceeded. This induces that for analyzing the compressive force the value of at least $0.5 t$, which lies nearby, should be considered for evaluation of the process, since it guarantees reaching the core of the belt, which determines the strength of the belt.

In order to find the correlation between the punch geometry and the material resistance force, the peak values of the force were derived based on the FEM analysis for a punch with diameter $D=10 \mathrm{~mm}$ and various punch radiuses in range of 5.5 to $10 \mathrm{~mm}$ (Fig. 6a). The growing tendency with the increase of the bowl radius is visible and it can be approximated with a linear correlation without errors greater than the FEM model precision. If we consider punches with the same bowl radius $R=7.25 \mathrm{~mm}$ and various diameters $D=5,6,8$, and $10 \mathrm{~mm}$ (Fig. 6b), the monotonicity of the function is preserved, but the correlation is non-linear. It can be caused by the dual influence of the diameter $D$ change with constant bowl radius $R$-it increases the length of the cutting edge, which affects the force necessary to generate stress in the shearing cross-section and improves the sharpness of the tool, which should speed up the failure of the belt core. Nevertheless, both of the characteristics proved the thesis that the correlation between the resistance force of the compressed material of the multilayer polymer composite belt during punching and the efficiency of the process exists.

To specify this correlation, the experimental tests of the compressive resistance of the material for the belt TFL10S and spherical bowl punches with diameter $D=10 \mathrm{~mm}$ and various bowl radiuses were performed according to the methodology presented in Section 2. The results of the force measurement are presented in Fig. 7. As can be observed, the characteristics for different tools are consistent at the beginning, when the failure does not occur, but starts to differ after the cutting edge starts to separate the layer of material from the scrap. As was stated at the beginning of this section, the value which precisely reflects the efficiency

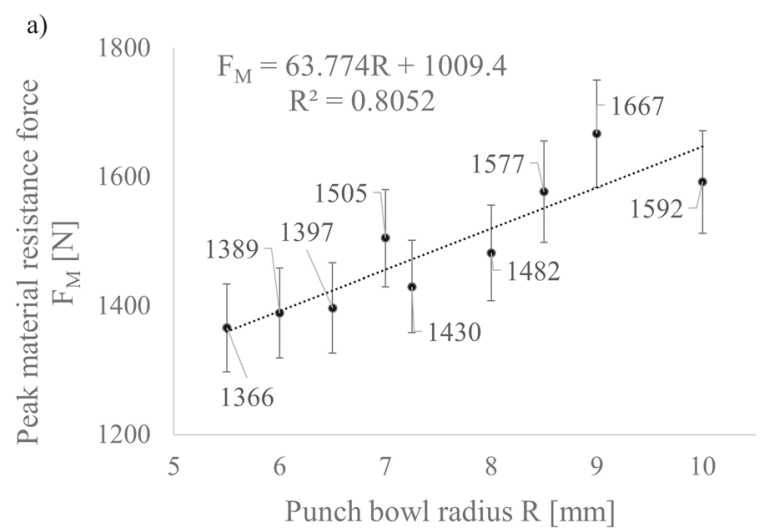

of the perforation process is the force magnitude for depth of penetration $h=1.5 \mathrm{~mm}$. These values were used in the characteristic presented in Fig. 8a. The obtained results proved that the linear correlation between the material resistance compressive force $F_{C M P}$ and the geometry of the punch (the punch bowl radius $\mathrm{R}$ ) exists. To verify the correctness of the thesis, the same experimental tests were conducted for the belt LAB12E with extremely different mechanical properties and the results are presented in Fig. 8b.

As can be observed, both characteristics present the same tendency, which broadens the spectrum of application for such a tool quality control method. Since the presented methodology is non-invasive for the piercing punch and requires only a small piece of the tested belt, it can be easily used to evaluate the sharpness of the cutting edge. If the obtained results lie too far from the derived characteristic for the selected belt type, it follows that the tool condition is not proper and should be corrected before it will be allowed to be used. If the measured value lies over the estimation line, it means that the sharpness is lower than it should be, while the results lying below the line may be characterized with a shorter tool life. Based on these results, the factory quality standards can be determined.

Although this approach can be useful in the manufacturing process, it does not provide information about the efficiency of the process. In order to be able to evaluate this parameter, it is necessary to find the correlation between the measured force and the perforation force $F_{P}$ or the perforation force reduction parameter $P F R$, which represents the energy saving compared with using a basic flat piercing punch and is defined as follows:

$$
P F R=\frac{F_{F L A T}-F_{S B}}{F_{F L A T}} \cdot 100
$$

To achieve this goal, the results from previous research [6] and from the presented experimental tests are sum-

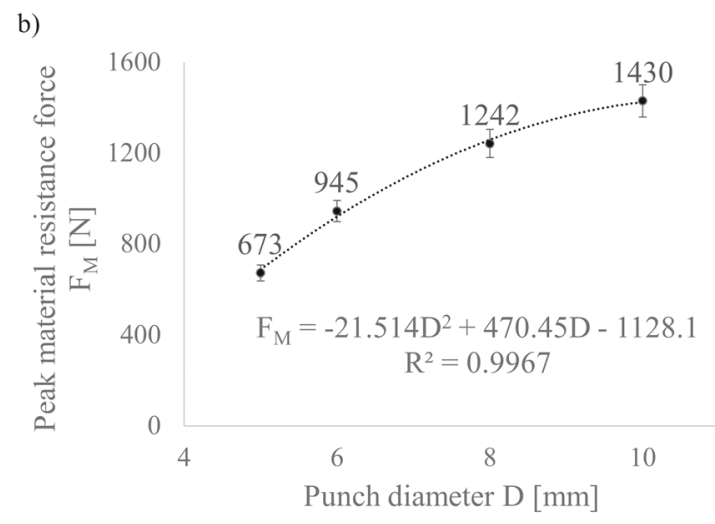

Fig. 6 The correlation between the variable punch bowl radius with punch diameter $D=10 \mathrm{~mm}(\mathbf{a})$ or the variable punch diameter with bowl radius $R=7.25 \mathrm{~mm}(\mathbf{b})$ and the peak material resistance force for TFL10S belt 
Fig. 7 Test results of the material resistance compressive force in function of punch displacement for various bowl radiuses $R$, punch diameter $D=$ $10 \mathrm{~mm}$, and TFL10S belt
Fig. 8 Correlation between the resistance compressive force for selected $h$ and bowl radiuses $R$ for punch diameter $D=10 \mathrm{~mm}$ and TFL10S (a) and LAB12E (b) belts

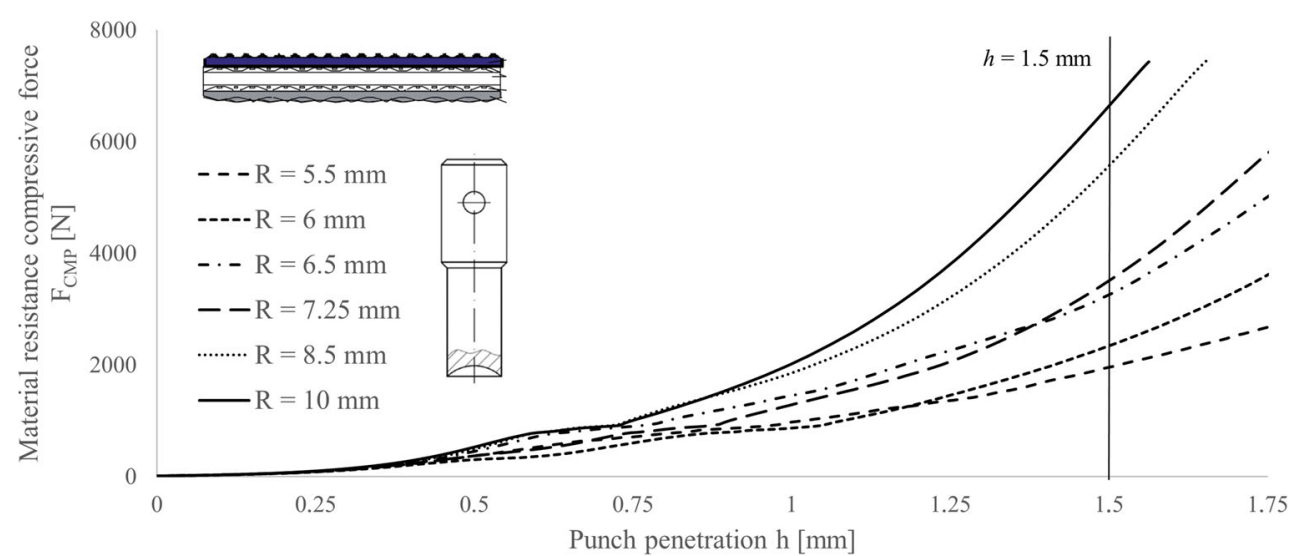

a)

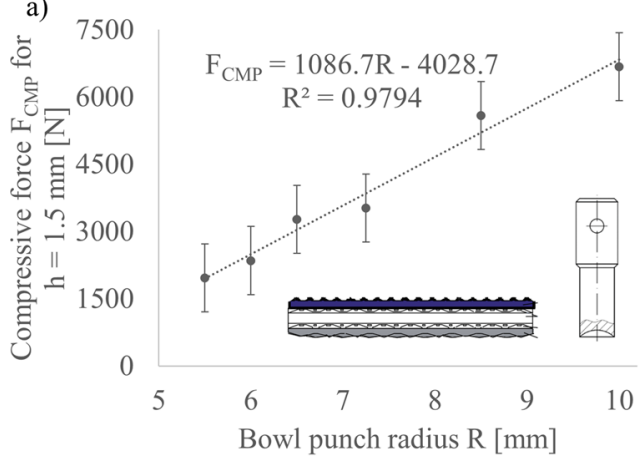

b)

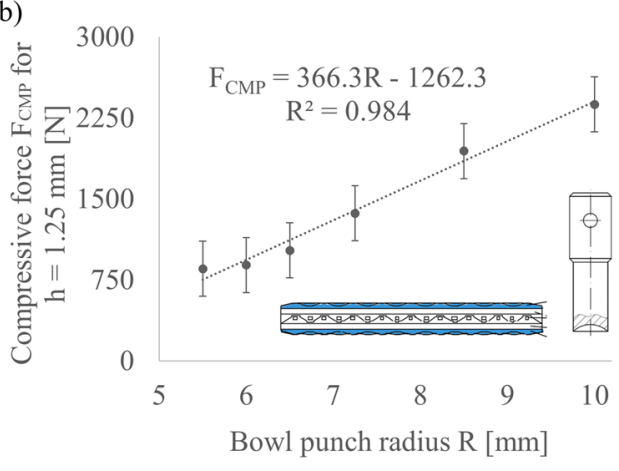

Table 2 Results of the compressive force measurement for various piercing punches and comparison with the force values obtained from FEM analyses and experiments

\begin{tabular}{llllll}
\hline $\begin{array}{l}\text { Punch } \\
\text { diameter }\end{array}$ & $\begin{array}{l}\text { Bowl } \\
\text { radius }(\mathrm{mm})\end{array}$ & $R$ & $\begin{array}{l}\text { Compressive } \\
\text { force } F_{C M P} \text { for } \\
h=1.5 \mathrm{~mm}(\mathrm{~N})\end{array}$ & $\begin{array}{l}\text { Perforation } \\
\text { force } \\
\text { spherical } \\
\text { bowl punch- } \\
\text { simulation } \\
F_{S B-F E M}[\mathrm{~N}]\end{array}$ & $\begin{array}{l}\text { Perforation } \\
\text { force } \\
\text { spherical } \\
\text { bowl punch- } \\
\text { experiment } \\
F_{S B-E X P}[\mathrm{~N}]\end{array}$
\end{tabular}


a)

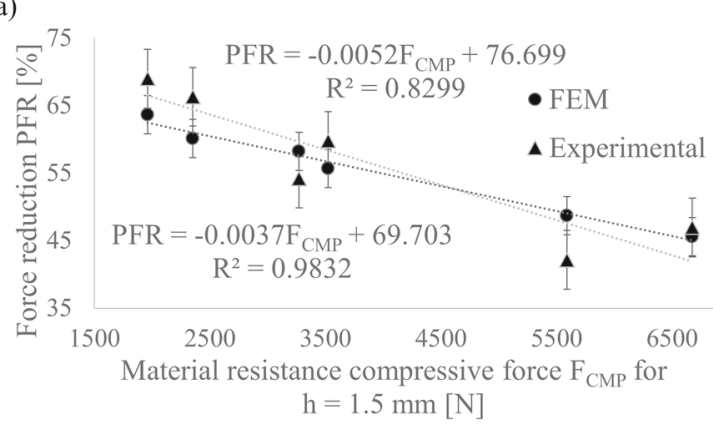

b)

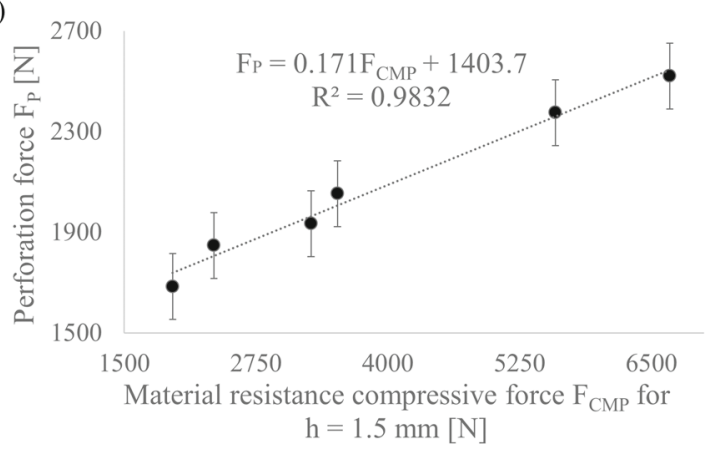

Fig. 9 Correlation between the material resistance compressive force for $h=1.5 \mathrm{~mm}$ and force reduction $P F R$ (a) or perforation force $F_{P}(\mathbf{b})$ for TFL10S belt

marized in Table 2. For the calculations, the perforation force for the flat punch with diameter $D$ was assumed as $4633 \mathrm{~N}$ [6]. The correlation between the $P F R$ and material resistance compressive force $F_{M}$ for both simulation and experimental tests is presented in Fig. 9a. As can be observed in both cases, the linear correlation between these parameters is visible. The convergence for the simulation results is slightly better than for the experimental values since two of the tested punches had lower cutting edge quality. If we compare it with the analysis [6], we can easily see the resemblance.

Based on the above characteristics, we are able to evaluate the anticipated tool performance during the belt perforation process based strictly on the experimental results from a simple test using the developed methodology. The $P F R$ parameter is a relative one, which makes it a universal indicator which can be used to evaluate the process for any type of belt. However, for the application in the punching design process, it is required to know the peak perforation force for a selected belt type and a flat piercing punch in order to design the drive system of the machine (for example, to select a proper pneumatic actuator). To meet this requirement, the correlation between the material resistance compressive force $F_{M}$ and the peak perforation force $F_{P}$ has to be specified, as presented in Fig. 9b. The main disadvantage is the necessity to perform full research for at least the belt with the highest strength in order to properly select the drive for the punching machine.

This methodology of testing can be also used to evaluate the effective geometry of the piercing punch. If we analyze the characteristics (Fig. 10a) for the effective geometries of the punch for diameters $D=5,6,8$, and $10 \mathrm{~mm} \mathrm{[6],}$ we can observe the consistency of the characteristics, with only a slight deviation at the end of the measuring range. It follows that by testing the compressive material resistance force and comparing it with the obtained characteristics of the effective piercing punches, we are able to define how far from the optimal solution the manufactured tool is.

To analyze a small deviation in the force value for punch penetration $h=1.5 \mathrm{~mm}$ between each of the characteristics, the $P F R$ was calculated for each of the piercing punches (Table 3 ). The divergence is caused by the decreased ability for the perforation force reduction with a rising diameter of the punch. If we apply these values, the linear correlation between the $P F R$ and compressive resistance force $F_{C M P}$ can be found (Fig. 10b). This characteristic can be used for quality control of the cutting edge of the effective punches for belt perforation. Based on the perforation force estimating characteristics [6], we can predict the value of the force and by combining it with the values for a flat punch derived based on the model [13], we can calculate $P F R$
Fig. 10 Test results of the material resistance compressive force in function of punch displacement for effective bowl radius and various punch diameters $D$ and TFL10S belt (a) and the correlation between the force reduction $P F R$ and the material resistance compressive force for TFL10S belt (b) a)

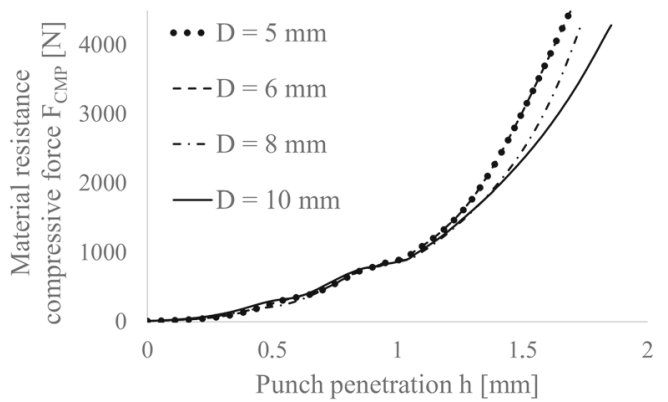

b)

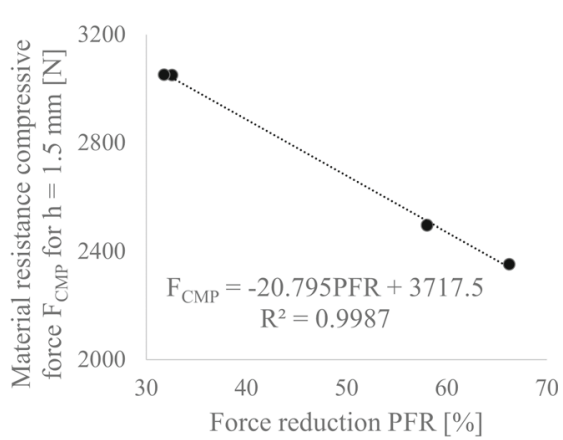


Table 3 Results of the compressive resistance force measurement for effective tools

\begin{tabular}{|c|c|c|c|c|c|}
\hline $\begin{array}{l}\text { Punch diameter } \\
D(\mathrm{~mm})\end{array}$ & $\begin{array}{l}\text { Effective bowl } \\
\text { radius } R(\mathrm{~mm})\end{array}$ & $\begin{array}{l}\text { Compressive } \\
\text { force } F_{C M P} \text { for } \\
h=1.5 \mathrm{~mm}(\mathrm{~N})\end{array}$ & $\begin{array}{l}\text { Perforation } \\
\text { force } F_{S B-E X P} \\
(\mathrm{~N})\end{array}$ & $\begin{array}{l}\text { Perforation } \\
\text { force for a flat } \\
\text { punch } F_{F L A T} \\
\text { (N) }\end{array}$ & $\begin{array}{l}\text { Force reduction } \\
P F R_{E X P}(\%)\end{array}$ \\
\hline 10 & 6 & 2352 & 1562 & 4633 & 66.3 \\
\hline 8 & 4.8 & 2494 & 1462 & 3485 & 58 \\
\hline 6 & 3.5 & 3051 & 1803 & 2643 & 31.8 \\
\hline 5 & 2.9 & 3049 & 1452 & 2155 & 32.6 \\
\hline
\end{tabular}

for a selected tool geometry. After manufacturing this tool, we are able to check if the measured compressive resistance force of the material is consistent with the predicted value of $P F R$. If the force $F_{C M P}$ is lower than expected, it means that the tool is sharper, which may lead to shortening its life. If the force $F_{C M P}$ is higher, it follows that the cutting edge is too blunt and the efficiency of the perforation process will be reduced (the perforation force will increase). Additionally, if we use the characteristic $F_{C M P}(P F R)$, we are able to calculate the magnitude of the changes in the process efficiency.

\section{Conclusions}

The presented research proved that the correlation between the resistance force of the compressed material of the multilayer polymer composite belt during punching and the efficiency of the process exists. The linear correlation between the compressive force and the bowl punch radius (for the same punch diameter) was found, which resulted in linear correlation with the perforation force and its reduction (PFR). It was evident in the results that, regardless of the punch diameter, if we have used effective geometry of the punch, the characteristics of compressive material force to the punch displacement were almost identical (especially in the beginning part). The estimated force value and its reduction corresponds with the experimental values obtained during the tests. It was also proved that using the effective geometry of the piercing punch with spherical bowl can reduce the perforation force by $69 \%$.

Based on the obtained model, the simplified optimization as well as the evaluation of the punches with a defined geometry can be performed. It can be very useful in the tool quality control during its manufacturing process to check the sharpness of the cutting edge of the piercing punch. For proper analysis, it is necessary to use the combination of the analytical and numerical modelling, computer simulations using the finite element method (FEM), and the experimental tests. However, by performing simple compression tests for various tool geometry on the strength testing machine, it is possible to perform the comparison analysis of different piercing punches based on the derived models. This approach can be used to evaluate the properties of selected tools for the groups of materials with a wide divergence of the mechanical properties without the need to perform complex research. Based on the abovementioned conclusions, this research provides a lot of useful information for both the scientific approach and industrial approach. Its further development is possible to refine the influence of process parameters like punch velocity or tool temperature.

Open Access This article is licensed under a Creative Commons Attribution 4.0 International License, which permits use, sharing, adaptation, distribution and reproduction in any medium or format, as long as you give appropriate credit to the original author(s) and the source, provide a link to the Creative Commons licence, and indicate if changes were made. The images or other third party material in this article are included in the article's Creative Commons licence, unless indicated otherwise in a credit line to the material. If material is not included in the article's Creative Commons licence and your intended use is not permitted by statutory regulation or exceeds the permitted use, you will need to obtain permission directly from the copyright holder. To view a copy of this licence, visit http:// creativecommonshorg/licenses/by/4.0/.

\section{References}

1. Soares JA, Gipela ML, Lararin SF, Marcondes PVP (2013) Study of the punch-die clearance influence on the sheared edge quality of thick sheets. Int J Adv Manuf Technol 65:451-457. https://doi.org/10.1007/s00170-012-4184-2

2. Mucha J, Tutak J (2019) Analysis of the influence of blanking clearance on the wear of the punch, the change of the burr size and the geometry of the hook blanked in the hardened steel sheet. Materials 12:1261:1-16. https://doi.org/10.3390/ma12081261

3. Vinod LH, Shivashankar RS (2018) Sheet metal forming processes - recent technological advances. Materials Today: Proceedings 5, 2564-2574

4. Djavanroodi F, Abbasnejad DS, Nezami EH (2011) Deep drawing of aluminum alloys using a novel hydroforming tooling. Mat Manuf Process 26(5):796-801. https://doi.org/10.1080/ 10426911003720722

5. Boljanovic V (2012) Sheet metal stamping dies die design and die making practices. Industrial Press Inc., United States 
6. Wojtkowiak D, Talaśka K (2019) Determination of the effective geometrical features of the piercing punch for polymer composite belts. Int J Adv Manuf Technol 104(1-4):315-332. https://doi.org/10.1007/s00170-019-03746-7

7. Wojtkowiak D, Talaśka K, Malujda I, Domek G (2017) Vacuum conveyor belts perforation - methods, materials and problems. Mechanik. https://doi.org/10.17814/mechanik.2017.12.192

8. Spagnoli A, Terzano M, Brighenti R, Artoni F, Stahle P (2018) The fracture mechanics in cutting: a comparative study on hard and soft polymeric materials. Int J Mech Sci 148:554-564. https://doi.org/10.1016/j.ijmecsci.2018.09.013

9. Durante M, Boccarusso L, De Fazio D, Langella A (2019) Circular cutting strategy for drilling of carbon fiber-reinforced plastics (CFRPs). Mat Manuf Process 34(5):554-566. https://doi.org/10. 1080/10426914.2019.1566615

10. Anand RS, Patra K (2018) Cutting force and hole quality analysis in micro-drilling of CFRP. Mat Manuf Process 33(12):1369-1377. https://doi.org/10.1080/10426914.2017.1401715

11. Chan HY, Abdullah AB, Samad Z (2015) Precision punching of hole on composite panels. Indian J Eng Mater Sci 22:641-651. https://doi.org/10.1063/1.5010491

12. Zain MSM, Abdullah AB, Samad Z (2017) Effect of puncher profile on the precision of punched holes on composite panels. Int J Adv Manuf Technol 89:3331-336. https://doi.org/10.1007/ s00170-016-9339-0

13. Wojtkowiak D, Talaśka K, Malujda I, Domek G (2018) Estimation of the perforation force for polymer composite conveyor belts taking into consideration the shape of the piercing punch. Int $\mathrm{J}$ Adv Manuf Technol 98(9-12):2539-2561. https://doi.org/10.1007/ s00170-018-2381-3

14. Wojtkowiak D, Talaśka K (2019) The influence of the piercing punch profile on the stress distribution on its cutting edge. MATEC Web Conf 254:02001

15. Wojtkowiak D, Talaśka K, Malujda I, Domek G (2018) Analysis of the influence of the cutting edge geometry on parameters of the perforation process for conveyor and transmission belts. MATEC Web of Conf 157:01022

16. Wojtkowiak D, Talaśka K (2019) Modelling the belt perforation process with the piercing punch and the die in the context of the construction of the punching dies. IOP Conf Series: Mater Sci Eng 647:012013

17. Lamikiz A, Lopez de Lacalle N, Celaya A (2009) Machine tool performance and precision - chapter 6. In: Lopez de Lacalle N., Lamikiz A. (eds) Machine tools for high performance machining. Springer, London, pp 219-260

18. Reilly GA, McCormack BAO, Taylor D (2004) Cutting sharpness measurement: a critical review. J Mat Process Technol 153154:261-267. https://doi.org/10.1016/j.jmatprotec.2004.04.297

19. McCarthy CT, Hussey M, Gilchrist MD (2007) On the sharpness of straight edge blades in cutting soft solids: part I - indentation experiments. Engng Fract Mech 74:2205-2224. https://doi.org/10. 1016/j.engfracmech.2006.10.015

20. McCarthy CT, Annaidh AN, Gilchrist MD (2010) On the sharpness of straight edge blades in cutting soft solids: part II - analysis of blade geometry. Engng Fract Mech 77:437-451. https://doi.org/10.1016/j.engfracmech.2009.10.003

21. Schuldt S, Arnold G, Roschy J, Schneider Y, Rohm H (2013) Defined abrasion procedures for cutting blades and comparative mechanical and geometrical wear characterization. Wear 300: $38-43$
22. Lau KH, Mei D, Yeung CF, Man HC (2000) Wear characteristics and mechanisms of a thin edge cutting blade. J Mat Process Technol 102:203-207. https://doi.org/10.1016/S0924-0136(99) 00410-0

23. Van Woerden S (2016) A study of non-contact knife sharpness analysis. Albany, New Zealand, Master thesis. Massey University

24. Lu S, Gao Y, Xie T, Xie F, Jiang XQ, Li Z, Wang F (2001) A novel contact/noncontact hybrid measurement system for surface topography characterization. Int J Mach Tools Manuf 41:20012009. https://doi.org/10.1016/S0890-6955(01)00064-5

25. Sandak J, Pałubicki B, Kowaluk G (2011) Measurement Of the cutting tool edge recession with optical methods. In: Proceedings of the 20th International Wood Machines Seminar, Sweden, June 7-10, 2011, Luleå University of Technology: Skellefteå

26. Patel KK, Kar A, Jha SN, Khan MA (2012) Machine vision system: a tool for quality inspection of food and agricultural products. J Food Sci Technol 49(2):123-141. https://doi.org/10.1007/s131 97-011-0321-4

27. Flisram DG, Rattmann JA, Skaar GR, Holmes TL (1995) Measurement of cutting edge sharpness. US Pat. 5,379,633, January 10, 1995

28. Lebouitz KS, Migliuolo M (2002) Cutting instrument having integrated sensors. US Pat. 6,494,882, December 17, 2002

29. Lebeau RC (2006) Optical sharpness meter. US Pat. App. 0192939 A1, August 31, 2006

30. CATRA Sharpness tester. http://www.catra.org (accessed $14^{\text {th }}$ October 2019)

31. Shetty N, Shahabaz SM, Sharma SS, Shetty SD (2017) A review on finite element method for machining of composite materials. Composite Struct 176:790-802

32. Dandekar CR, Shin YC (2012) Modeling of machining of composite materials: a review. Int $\mathrm{J}$ of Mach Tools \& Manuf $57: 102-121$

33. Zhou L, Huang ST, Wang D, Yu XL (2011) Finite element and experimental studies of the cutting process of $\mathrm{SiCp} / \mathrm{Al}$ composites with PCD tools. Int J of Adv Manuf Technol 52:619626

34. Dandekar CR, Shin YC (2009) Multi-step 3D finite element modeling of subsurface damage in machining particulate reinforced metal matrix composites. Compos Part A 40(8):12311239

35. Talaśka K, Wojtkowiak D (2018) Modelling a mechanical properties of the multilayer composite materials with the polyamide core. MATEC Web of Conf 157:02052

36. Bassoli E, Sola A, Denti L, Gatto A (2019) Experimental approach to measure the restraining force in deep drawing by means of a versatile draw bead simulator. Mat Manuf Process 34(11):12861295. https://doi.org/10.1080/10426914.2019.1628267

37. Zhou D, McMurray GV (2010) Modeling of blade sharpness and compression cut of biomaterials. Robotica 28(2):311-319. https://doi.org/10.1017/S0263574709990385

38. McGorry RW, Dowd PC, Dempsey PG (2005) A technique for field measurement of knife sharpness. Appl Ergon 36(5):635-640. https://doi.org/10.1016/j.apergo.2005.04.001

39. PolySprint ${ }^{T M}$ for printing machine and book binding machine. PolyBeltTM for Textile Industries. www.nitta.de (accessed $14^{\text {th }}$ October 2019)

Publisher's note Springer Nature remains neutral with regard to jurisdictional claims in published maps and institutional affiliations. 